\title{
Function-Based Classification: Model Development and Validation
}

\author{
Umi Asma' Mokhtar, Zawiyah M. Yusof \\ Faculty of Technology and Information Science, Universiti Kebangsaan Malaysia, 43600 Bangi, Selangor, \\ Malaysia \\ Email: umimokhtar@ukm.edu.my, zawiy@ukm.edu.my
}

Received October 2014

\section{Abstract}

Classification is a key element of records management initiatives, ensuring systematic organization of documents and facilitates information retrieval. Records management initiatives are based on the lifecycle concept, which comprises of creation, usage, maintenance (classification and organization), appraisal, and disposal. However, classification system is not prevalent in records management compared to other information field such as library where the concept differed in application and connotations. Although classification is crucial for disposal purpose, research addressing the issue is scarce, as past studies limited their focused to the earlier part of the records' life cycle i.e. storage and retrieval. This study examines classification from a records-management perspective by adopting the qualitative approach. Also it discusses the development of functional-based model and its validation. The proposed model consists of context and decomposed diagrams to illustrate classification processes. The process for validating the model consists of two phases. The first phase is the draft model by means of expert validation, conducted to validate the content and the context of classification process. The second phase of validation was aimed at validating the model in accordance with eight criteria. Further discussion of the findings concerns these seven criteria: content, scope, consistency, comprehensiveness, tailorability, process sequence, and overall impression. The findings revealed that the proposed model is a basic model that is crucial as a guidance for developing records classification. Moreover, the proposed model is timely, as there is as yet no such a model known as a functional model for classifying records.

\section{Keywords}

Records Management, Function-Based Classification, Classification, Expert Validation, Functional Model

\section{Introduction}

Although classification is a key element of records management (RM), it is under-explored compared to other elements such as guidelines, standards, appraisal, and preservation. This paper discusses the development of a proposed records classification model; its validation has been based on the expert validation technique. Analysis of existing models on records classification (RC) has revealed that most models have been represented in leng- 
thy textual form, and are generic and presented together with either functional requirements or guidelines. The proposed model is represented in function modelling of RC, including all elements and activities involved in classifying records. The function modelling would enable the communication between information technology (IT) and RM professionals. Functional models act as structured representations of functions in a modelled system or subject area [1].

\section{Method}

This study has adopted a qualitative approach to examine the implementation of a classification system with reference to Department of Judiciary Syariah Malaysia in Malaysia, using both the interview and content analysis techniques. Upon obtaining information about the system of classification in the identified department, a model has been proposed using IDEF0 which is a tool for functional modelling, assisted by ConceptDraw PRO software. The proposed model is then validated using the expert validation technique.

\section{Model Development}

The development of the model has been carried out by identifying its main elements, such as function, action, and organizational structure [2] [3]. The action element is the foremost element to be considered since most records are by-products of actions which fall into groups that relate to those actions. Actions are synonymous with activities in models, referring to functions, activities, transactions, and processes [3]. The model presented in this paper has been developed by taking into consideration both RM principles and archival science theory. RM principles focuses on the management of current records, while the archival science theory complies with the principles of respect des fonds and provenance theory.

The proposed model, later referred to as the Records Classification Model (FRCM), focuses on the first phase of recordkeeping functional requirements, namely "Create". The main concern when creating records, from the RM perspective, is to ensure that records are created in context by ensuring its metadata, management of aggregations, and classification tools. The creation of records requires a disposition schedule, capture methods, metadata elements, forms and structure, and technology solutions. Records are controlled using processes such as registration, classification, selection, access rules, authorizing use, disposition, transfer, removing, destruction and administration of records systems. Therefore, the classification of records occurs at the 'Create' phase, which is the focus of interest of this study.

The development of the FRCM comprises of processes, such as Node Index, Context Diagrams, and Decomposed Diagrams. The proposed FRCM serves as a foundation guideline in identifying functions in organizations for the purpose of classifying records. The proposed FRCM is not a classification scheme; however, a classification scheme can be developed by referring to this model.

A node index (Figure 1) is used as a guide or index to list the related functions, which are then drawn into the context diagram. The context diagram is the highest level diagram, and is made up of all inputs, controls/constraints, outputs, and mechanisms. In the IDEF0 model, these four components are used to represent all related activities or components involved in the model. The context diagram is decomposed to lower level diagrams, in order to give further detail about the processes involved.

The node index is a simple way to portray both the "create" and "capture" processes as incorporated in the "Manage Records Creation” element. After the node index was identified, a context diagram was drawn and named as Diagram A-0 (Figure 2), describing the subject of the model and its overall context as represented in a single box with its bounding arrows. The bounding arrows represent the model's inputs, outputs, controls or constraints, and mechanisms. The inputs for the "Manage Records Creation" are information, author, and action. These inputs are controlled by guidelines of creators' mandates and functions; laws and regulations; de jure standards; and creators organizational structure. The mechanisms for the 'Manage Records Creation' include the records manager, physical facilities, and infrastructure and information technology. There are two outputs which are create and capture/save processes.

Diagram A-0 decomposes the single process (Manage Records Creation) into sub-processes as represented in various levels. The Diagram A-0 enable both records managers and IT personnel to perform their jobs efficiently and comply with the relevant rules in records classification, intrinsic element in the creation, maintenance, storage and disposal of electronic records. Diagram A-0 also shows the management of records creation at the highest level. It is simple but difficult to understand the function without decomposing the processes into separate levels: 


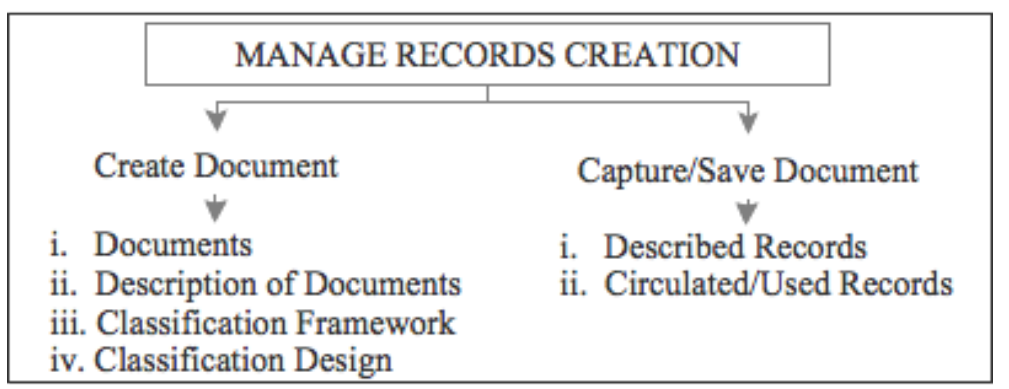

Figure 1. Node index.

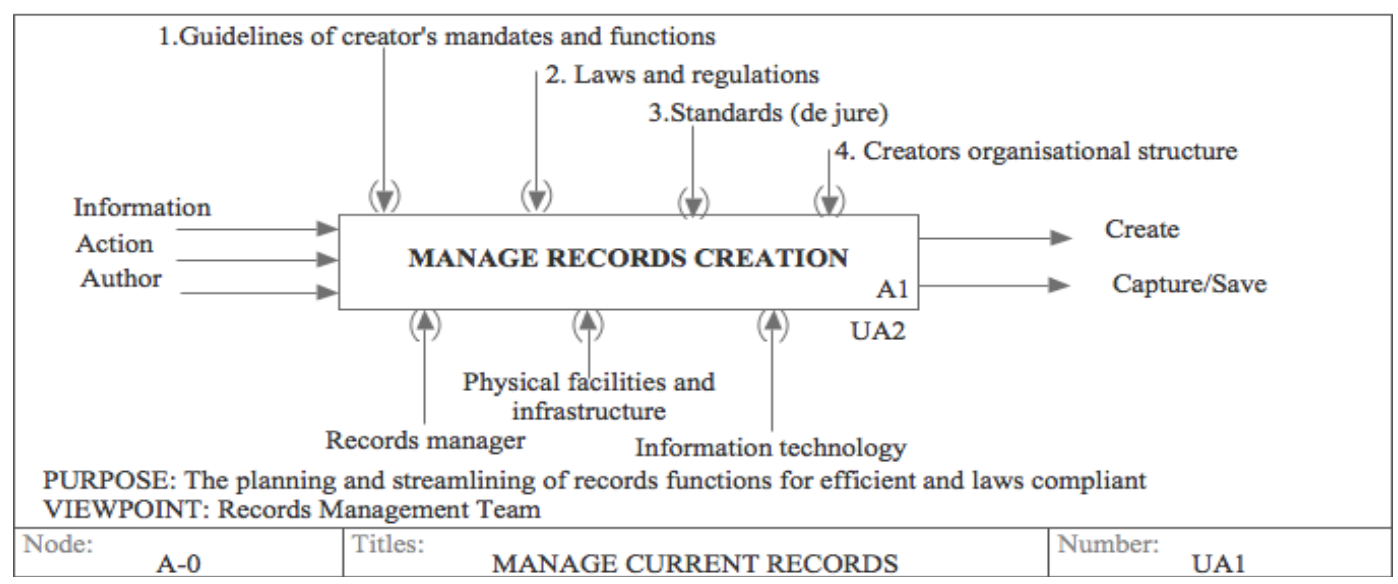

Figure 1. Context diagram (Diagram A-0)

first, second and third levels.

The first level diagram describes the content of the context diagram which depicts the processes involved, including the creation of documents and capture/saving of documents. These stages further broken down into the second and third levels. The second level depicts the process for creating documents. Once the document is created or received, details such as information about the author, actions involved in creating the document, contents, structure, and context are composed into descriptions of documents. The document consists of contents and descriptions. The descriptions of documents are presented in a structured form, known as metadata. Particulars such as inputs, constraints, and mechanisms which are needed while creating a document are gathered to form a classification framework and design. The third level shows simpler processes involved in the capture/ save documents. The documents retrieved are captured, while the documents created are saved. Both share a similar function, which is to save the document into the system prior to determining whether a document is a record.

\section{Model Validation}

Model validation is typically carried out to address the right problem, providing accurate information about the system being modelled to be implemented in the real world. Experts in records classification were selected to represent both the theorists (academicians) and professionals (practitioners). The experts were selected based on their experience in classification field. The expert validation has been an ideal approach by referring the 'experts' with respect to the system [4]. The expert panel validation approach is adopted in many researches to validate the contents and requirements processes [5] [6]. The seven experts, from Asia (China), the Middle East (Cairo), North America (USA and Canada) and Australia, were chosen due to their credibility and knowledge in classification; and representing the country which has strong research and practice in RM. The validation process was done on-line (electronic mail) with two attachments, questionnaire and model. The response rate achieved for this study is regarded as "acceptable and desired" at above 60 percent [7]. The findings from the validation are categorized into seven criteria. The results are tabulated in Table 1. 
Table 1. Results from expert's validation.

\begin{tabular}{|c|c|}
\hline Criteria & Result \\
\hline Content & $\begin{array}{c}\text { The FRCM is able to identify and prioritize the processes involved based on the descriptions given, and able to } \\
\text { customize the model for organization's needs. }\end{array}$ \\
\hline Scope & $\begin{array}{l}\text { The FRCM includes all the FRCM relevant process of classification with each } \\
\text { process relates to the classification activities. The FRCM also provides an appropriate flow of input and } \\
\text { output for developing a classification system. }\end{array}$ \\
\hline Consistency & $\begin{array}{c}\text { The respondents are "satisfied” with the consistency of details, outlined key processes, sequence of process order, and } \\
\text { explanation given for each diagram. }\end{array}$ \\
\hline Comprehensiveness & $\begin{array}{l}\text { Each process composed in the FRCM is easy to understand and able to help practitioners understand better from the } \\
\text { context diagram into decomposed levels, and the model is presented clearly to help understand the process and flow of } \\
\text { each process with ease. }\end{array}$ \\
\hline Tailorability & $\begin{array}{l}\text { The possibility of each process to be enhanced in order to create specific guidelines and prescriptions. Also, the } \\
\text { activities outlined the FRCM are generalizable and likely to be applicable to most companies. }\end{array}$ \\
\hline Overall impression & $\begin{array}{c}\text { The results show that } 58 \text { percent respondents "agree” that IT department needs to continue } \\
\text { developing the classification by using this model as basic guidance. It is also useful for the research community to } \\
\text { continue developing this model and this is agreed by } 43 \text { percent of respondents. } \\
\text { Also, } 71 \text { percent of respondents "agree" that the FRCM is important as a foundation guideline } \\
\text { for each level of knowledge to develop classification system and this could contribute to } \\
\text { the body of knowledge and enrich the literature in RC. }\end{array}$ \\
\hline
\end{tabular}

\section{Discussion}

Function-based classification has gained a reputation in the RM field since its introduction by Schellenberg in the early 1950s. Many organizations have moved from subject-based classification to function-based classification due to its advantages. Model with structures and elements clearly labelled for developing a classification scheme is helpful, as users prefer it [8]. Proper techniques are required to hierarchically list functions. However, in real-world situations, structures or elements may be unclear, thereby creating an artificial and logical model which may serve as a true representation of the real world. Problems may arise if organizational structure is attached to a classification group, because it could become meaningless if the organization is re-structured or if staff transfer to different departments. To overcome this problem, a dynamic classification system may attach metadata to records to place them into virtual categories for the purpose of aiding retrieval function.

\section{Acknowledgements}

We would like to thank Universiti Kebangsaan Malaysia and Department of Syariah Judiciary Malaysia for giving the time, space and resources to carry out this research.

\section{References}

[1] IDEF (1993) Integration Definition for Function Modeling (IDEF0) Draft, Federal Information Processing Standards Publication FIPSPUB 183. U.S. Department of Commerce, Springfield, Virginia.

[2] Schellenberg T.R. (1956) Modern Archives Principles and Techniques. The University of Chicago Press, Chicago.

[3] Alberts, I., Schellinck, J., Eby, C. and Marleau, Y. (2010) Bridging Functions and Processes for Records Management. Canadian Journal of Information and Library Science, 34, 365-390. http://dx.doi.org/10.1353/ils.2010.0010

[4] Hillston, J. (2003) Model Validation and Verification. Teaching Notes. http://www.inf.ed.ac.uk/teaching/courses/ms/notes/note14.pdf

[5] Beecham, S., Hall, T., Britton, C., Cottee, M. and Rainer, A. (2005) Using an Expert Panel to Validate a Requirements Process Improvement Model. Journal of Systems and Software, 76, 251-275. http://dx.doi.org/10.1016/j.jss.2004.06.004

[6] Mathew, S.N., Field, W.E. and French, B.F. (2011) Content Validation Using an Expert Panel: Assessment Process for Assistive Technology Adopted by Farmers with Disabilities. Journal of Agricultural Safety and Health, 17, 227-241. http://dx.doi.org/10.13031/2013.38184

[7] Richardson, J.T.E. (2005) Instruments for Obtaining Student Feedback: A Review of the Literature. Assessment \& Evaluation in Higher Education, 30, 387-415. http://dx.doi.org/10.1080/02602930500099193

[8] Orr, S.A. (2005) Functions-Based Classification of Records: Is It Functional? Master Thesis, University of Northumbria, Newcastle. 